\title{
Altitude Measurement And Processing of Their Values
}

\author{
Pavel Pokorný \\ Faculty of Applied Informatics, Tomas Bata University in Zlin
}

\begin{abstract}
The main task of this paper is to describe altitude measurement methods and specify how to process the obtained altitude values for better use. Altitude is a very important parameter that affects many human activities like geographical surveys, geometry, aviation, sport, and more. For these reasons, it is necessary to measure altitudes and to process the obtained values in order to use them wherever it is needed. Some different altitude measurement methods will be described, a characteristic of the existing altitude measurement projects on Earth will be outlined and finally, design a way how to process the large amount of this data in the next step in order to make a visualization of a part of the Earth's surface.
\end{abstract}

Keyword: Measurement; data; modelling; algorithms; data processing; altitude
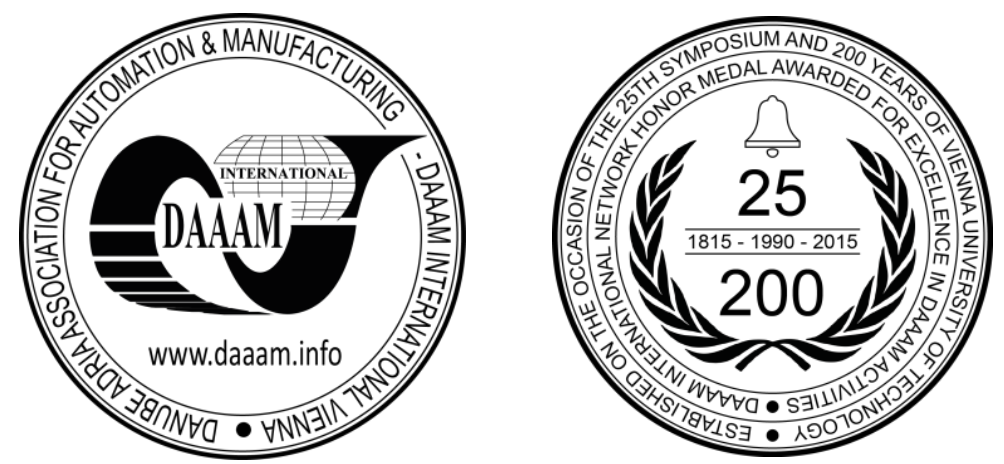

This Publication has to be referred as: Pokorny, P[avel] (2016). Altitude Measurement and Processing of their Values, Proceedings of the 26th DAAAM International Symposium, pp.0280-0285, B. Katalinic (Ed.), Published by DAAAM International, ISBN 978-3-902734-07-5, ISSN 1726-9679, Vienna, Austria

DOI:10.2507/26th.daaam.proceedings.038 


\section{Introduction}

The term altitude can be defined as the height of a location above a given planetary reference plane; in the case of our planet - Earth, this begins at sea level and up to the stratosphere, or down to the depths of the seas. This term is sometimes known as height or depth and it is often used in geometry, aviation, sport, geographical surveys and others. Indeed, altitude affects humankind's life in many aspects as described here in below, so it is necessary to measure it and to include the obtained values in the wide spectrum of human activities.

The obtained altitude is closely related to some important variables. One of them is air pressure [9]. As altitude increases, the atmospheric pressure decreases. This means that, in a given volume of air, there are fewer molecules present, including oxygen [3] [8]. The dependency of the atmospheric pressure based on the equivalent Earth altitude is shown in Figure 1, LEFT [10].
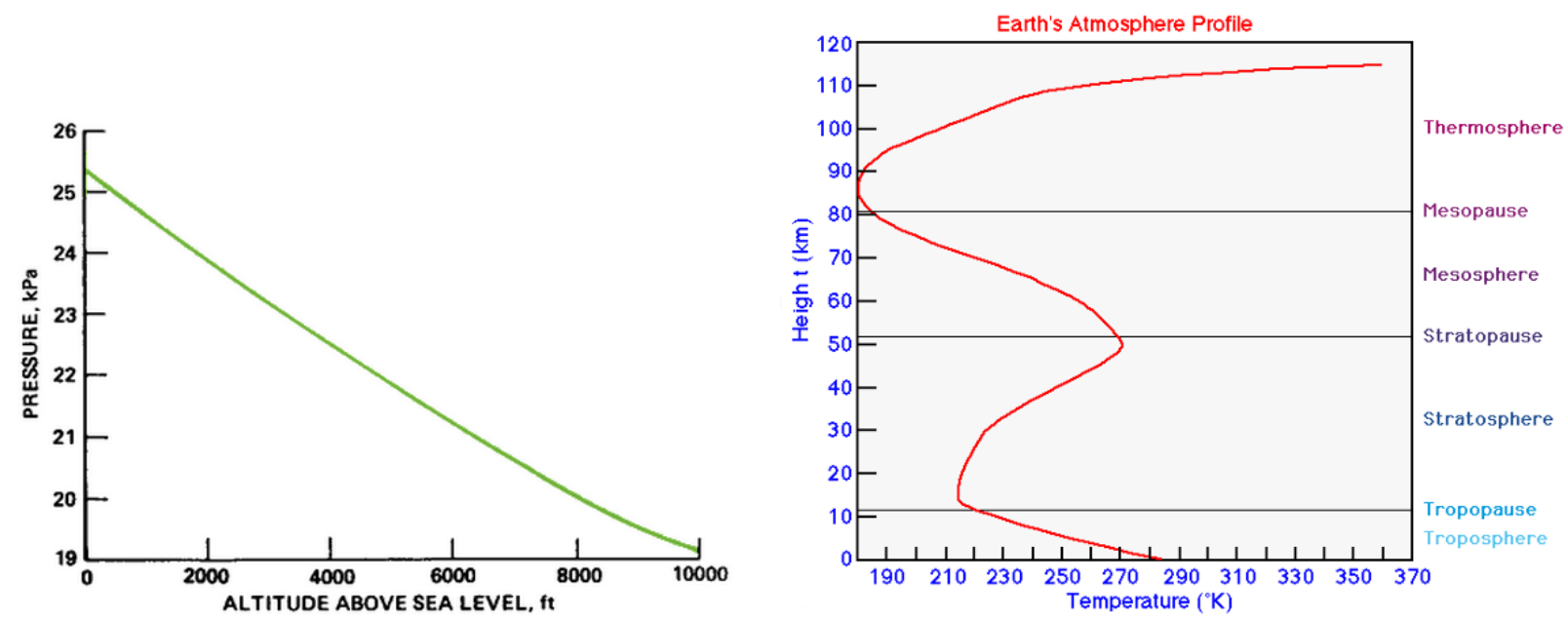

Fig. 1. (LEFT) Pure oxygen atmospheric pressure at the equivalent Earth altitude [10]; (RIGHT) The Earth's atmosphere profile related to altitude and temperature [12]

The other parameter that is closely linked to altitude is temperature. The relation between the temperature and altitude in the stationary atmosphere at a given time and location is specified by the environmental lapse rate [11]. In the lower regions of the atmosphere (up to altitudes of approximately 12,000 meters), temperature decreases with altitude at a fairly uniform rate. Because the atmosphere is warmed by convection currents from the Earth's surface, this lapse or reduction in temperature is normal due to increasing distance from the conductive source. The lapse rate of the Earth's atmosphere is shown in Figure 1 RIGHT [12].

\section{Altitude measurement methods}

Altitude measurement plays an important role in many fields of human interests - like aviation, geographic mapping or meteorological observations [4] [5]. In order to determine altitude (height), the following basic methods are the most commonly used [13]:

- Measurement by leveling - in the course of this measurement, the elevation of the two points is determined with the help of a leveling instrument

- Measurement by hydrostatic leveling - this method is based on physical laws of linked containers filled with a suitable liquid

- Measurement by trigonometry - the elevation is determined by the mathematical resolution of triangles [1]

- Measurement by atmospheric pressure - this measurement is based on barometric pressure; it uses the observation that atmospheric pressure decreases with altitude; with this method and using the modern microelectromechanical systems, the user can obtain high-precision altitude values [6]

- Measurement by radar - altitude is measured by a radar device, which generates microwave energy towards the ground and measures the received reflected energy waves; because speed, distance and time are all related to each other, the distance from the surface providing the reflection can be calculated; this method is often used on aircraft or spacecraft [2] [7]

The last two given methods mentioned above, are the most widely used. These methods and relevant technologies are mostly used to assist with GPS navigation, flight control and portable devices to conduct highprecision altitude measurements, positioning, navigation, etc. 


\section{Obtaining data about altitude on the Earth}

The previous chapter described methods, how to measure and obtain the altitude values. There were some projects in the past, which measured altitude on the Earth. One of them is a part of the Daft Logic resource collection [14]. With these resources, the user can find helpful tools and information and everything is available by means of modern web API tools and programming languages. The user interface of this project is linked to the Google Maps. A click on it creates a label in selected map and altitude information of this point is shown in the text area under this map (Figure 2). Other possibility to use this resource is represented by a field of altitude values that can be saved into output text file and process in the following steps. This is possible with the help of JavaScript code that uses Daft Logic and Google Maps API; also a description with an example is included with these resources.

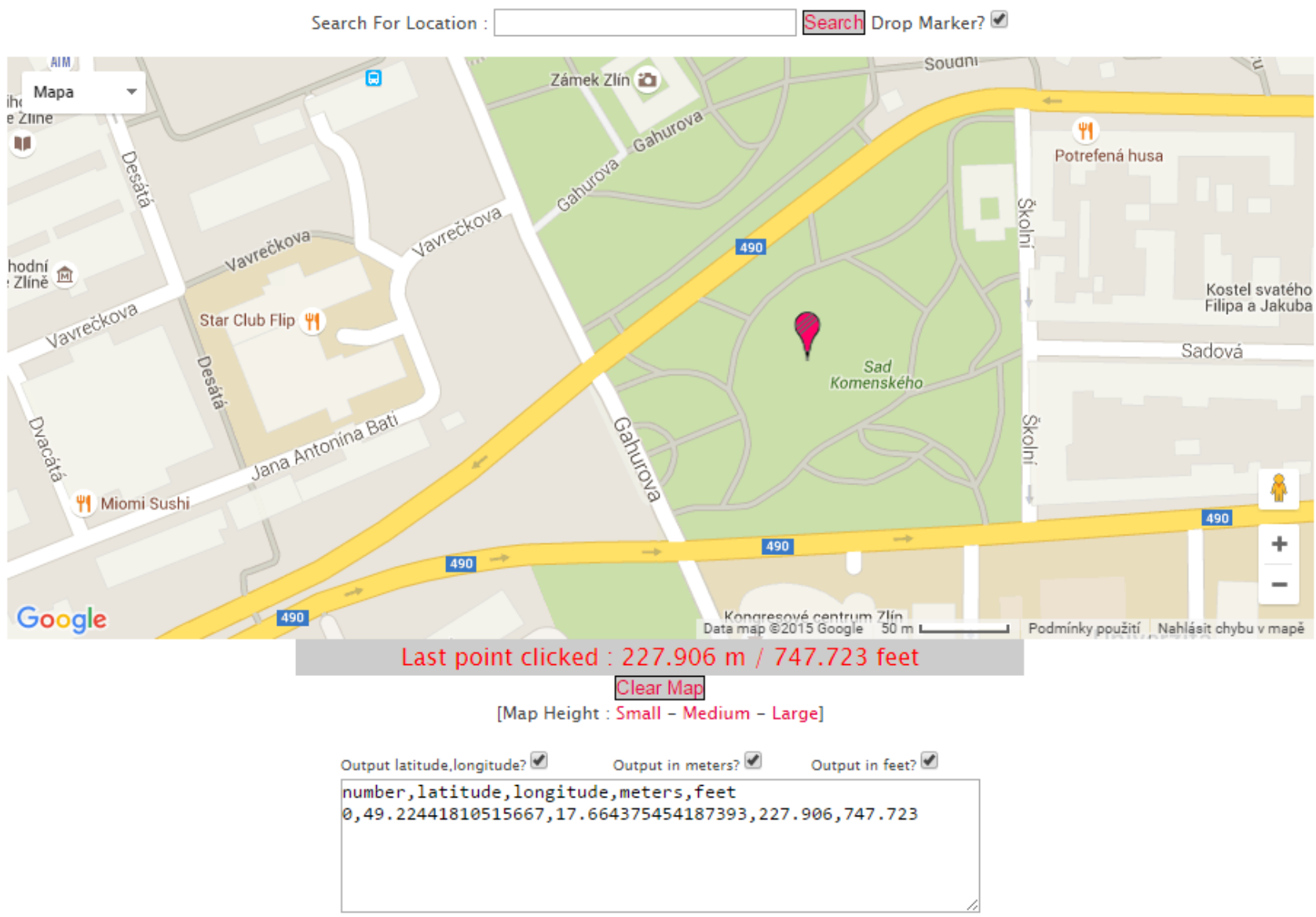

Fig. 2. The user interface of the Find Altitude Daft Logic project that uses Google maps

The other project is the Digital Elevation Model data (i.e. DEM) which was provided by the NASA Shuttle Radar Topographic Mission (SRTM) in 2007. The data for over $80 \%$ of the globe is stored on [15] and can be freely downloaded for noncommercial use. In order to obtain Earth altitude data, this project offers a plugin for the Google Earth application [16], where the Earth's surface is divided into quadrangles. By clicking on the selected quadrangle, a link to a file that can be downloaded is shown. This file contains whole altitudes of the selected area ordered in the ARC ASCII format. Because each quadrangle area is large and density of altitude is high, these files contain huge quantum of values and the size of a single file can exceed 15 gigabytes.

\section{Altitude data processing - an example}

As an example, a 3D landscape model of the real environment based on altitude was created. The landscape model of the city Zlín and its close vicinity was selected. In order to create it, the Digital Elevation Model data (described in the previous chapter) was used. Therefore, Google Earth [16] with DEM plugins were used and a file containing altitude of the area, where Zlín is, was downloaded. 


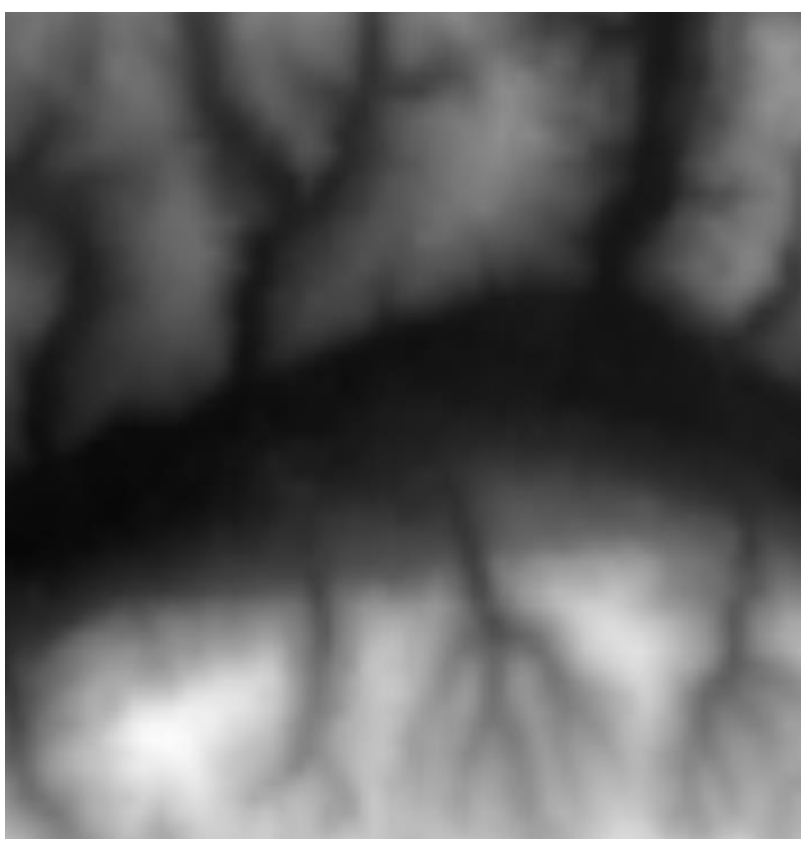

Fig. 3. The heightmap of Zlín's close vicinity

Because the file was too large and most of the altitude values were not necessary, the next step was to remove unwanted values and convert the remaining values into a grayscale bitmap image (e.g. a heightmap). The reason for the conversion process is because many 3D graphic applications support functions that allow one to quickly convert heightmaps into physical deformations of 3D objects. The Microdem software offers both operations (removing unwanted values and converting into a grayscale bitmap image) [17]. In Microdem, all these operations were applied in order to acquire the altitudes of the vicinity around Zlín. Specifically, a heightmap area of $25 \mathrm{~km} 2$ was created (a square with side lengths of $5 \mathrm{~km}$, centered on the center of Zlín - Figure 3). After that, this heightmap was saved into PNG raster graphic format (it is very important to use lossless compression) in order to use it in 3D software.

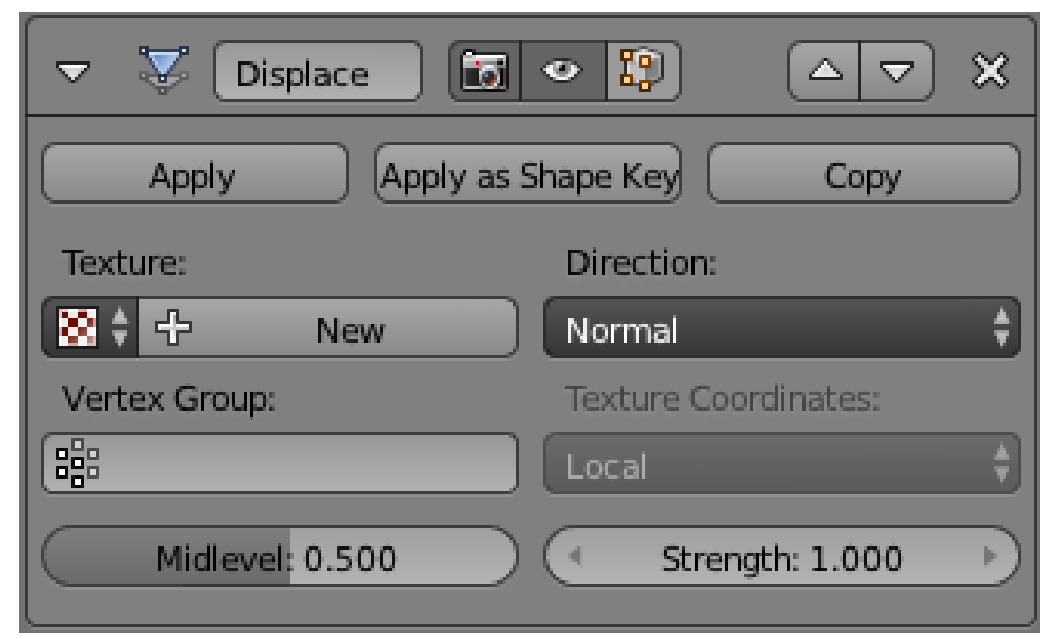

Fig. 4. Settings for the Displace modifier in the Blender environment

The Blender software suite was used as 3D software for the further processing of the heightmap [18]. Blender is available under open source license and supports the entirety of the 3D pipeline - fast and effective 3D modeling and rigging, rich animation tools, amazing simulations, photorealistic rendering, fledged compositing and motion tracking, even video editing and game creation.

In Blender, we inserted a square (the Plane object) in the new scene and we divided it several times with the Subdivide tool in order to get a grid with a density of several thousand vertices (higher precision can be reached by increasing density). Then, we used the Displace modifier and we assigned a texture (for the obtained heightmap) to it. The Displace modifier deforms an object based on the texture and setting parameters (Figure 4). This way, we derived the model of the Zlín vicinity's landscape using this method. The final wireframe mesh model of the Zlín vicinity's landscape is shown in Figure 5. 


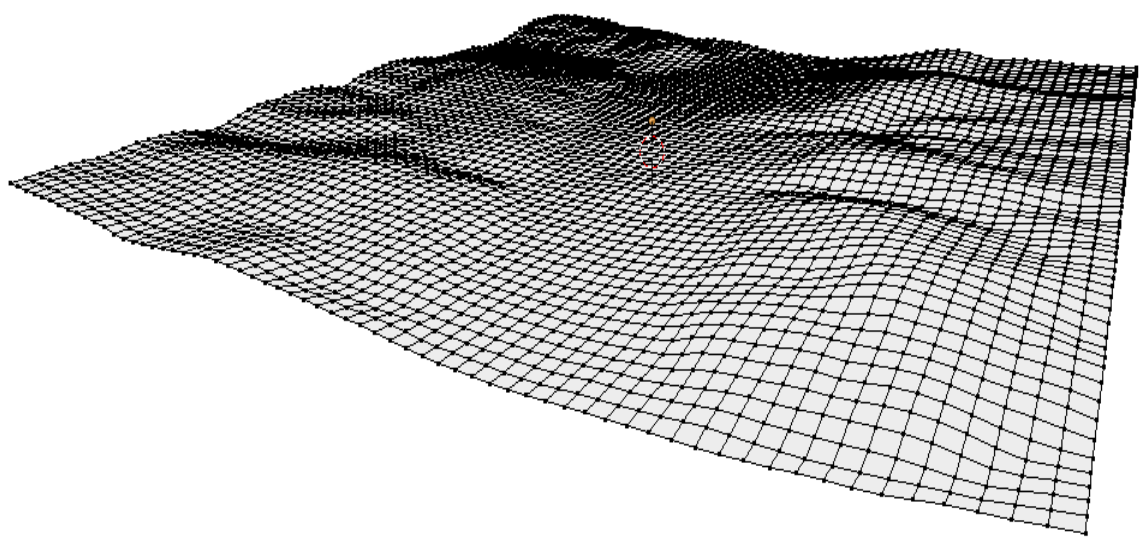

Fig. 5. The final mesh model of the Zlín vicinity’s landscape

\section{Conclusion}

Nowadays, high-precision barometric altitude measurement methods and relevant technologies are important tools in human life and many technical devices. Altitude affects a number of important parameters - such as temperature and pressure. That is why it is often necessary to measure it and to process the obtained data properly.

The most frequently used measurement methods are based on atmospheric pressure or with the help of radar devices. These methods, in conjunction with the corresponding hardware devices, can provide one with measured values of the highest precision. After the measuring process is completed, it is necessary to elaborate the whole set of values in order to use them in the follow-on processes. The elaboration method depends on the specific needs of this data. This paper presents an example of how to best use them in the course of the simulation process, where the real environment is visualized.

Visualizations of real environments are mainly used in Virtual Reality - which replicates an environment that simulates a physical presence in places in the real world, or imagined worlds, and allows the user to interact in that world. Due to this, the visualization process of real landscapes needs to have altitude values with the highest precision and the grid of measured values needs to have the highest possible density. Future research will therefore be oriented on these methods, processes and efforts to make them even more precise.

\section{References}

[1] R. Pellitero, B.R. Rea, M. Spagnolo, J. Bakke, P. Hughes, S. Ivy-Ochs, S. Lukas, A. Ribolini, A GIS tool for automatic calculation of glacier equilibrium-line altitudes, Computers \& Geosciences, 82, 2015, pp. 55-62, ISSN 0098-3004.

[2] K. L. Huang, C. C. Chiu, S. Y. Chiu, Y. J. Teng, S. S. Hao, Monocular Vision System for Fixed Altitude Flight of Unmanned Aerial Vehicles, Sensors (Switzerland), 15(7), 2015, pp. 16848-16865, ISSN 1424-8220.

[3] Q. Dai, X. Fang, A new model for atmospheric radiation under clear sky condition at various altitudes, Advances in Space Research, 54(6), 2014, pp. 1044-1048, ISSN 0273-1177.

[4] E. Manikandan, K.A. Karthigeyan, K. Immanuvel Arokia James, Micro electro mechanical system (MEMS) based pressure-sensor in barometric altimeter, International Journal of Scientific \& Engineering Research, 2011, pp. 1-3.

[5] Z. Zhu, S. Xiong, Z. Zhou, A micro barometric altimeter with applications in altitude-holding flight control for MAVs, Instrumentation and Measurement Technology Conference, 2004, pp.1039-1041.

[6] W. Zhu, Y. Dong, G. Wang, Z. Qiao, F. Gao, High-precision barometric altitude measurement method and technology, in: Information and Automation (ICIA), IEEE International Conference on Information and Automation, 2013. pp. 430-435.

[7] B. Chen, T. Hu, Z. Zheng, F. Wang, S. Zhang, Method of Altitude Measurement Based on Beam Split in VHF Radar and Its Application, in: Dianzi Xuebao(Acta Electronica Sinica), 2007, pp. 1021-1025.

[8] D. Z. Pavlinic, J. Balic, I. B. Mekjavic, Determination of the Thermoregulatory Specifications for Thermal Manikins, in: DAAAM International Scientific Book, B. Katalinic (Eds.), 2011, pp. 31-44.

[9] Altitude contributors (2015), Altitude.org [Online], available: http://altitude.org

[10] E. Bock, F. Lambrou, M. Simon, Effect of Environmental Parameters on Habitat Structural Weight and Cost [Online], available: http://www.nss.org/settlement/nasa/spaceres/II-1.html 
[11] M. Z. Jacobson, Fundamentals of Atmospheric Modeling (2nd ed.), Cambridge University Press, 2005, ISBN 0521-83970-X.

[12] Y. Kushnir (2000), Lapse Rate, Moisture, Clouds and Thuderstorms, Department of Earth \& Environmental Sciences, Columbia University [Online], available: http://eesc.columbia.edu/courses/ees/climate/index.html

[13] V. Čada, Výšky, jejich určování a referenční plochy, [Online], available: http://www.gis.zcu.cz/studium/gen1/html/ch10.html

[14] Daft Logic contributors (2013), Daft Logic [Online], available: http:// http://www.daftlogic.com/

[15] A. Jarvis, H. I. Reuter, A. Nelson, and E. Guevara. (2008). Hole-filled seamless SRTM data V4, International Centre for Tropical Agriculture (CIAT) [Online], available: http://srtm.csi.cgiar.org

[16] Google Earth contributors (2015), Google Earth [Online], available: http://www.google.com/intl/en/earth/

[17] Microdem contributors (2010), MICRODEM Home Page [Online], available at http://www.usna.edu/Users/oceano/pguth/website /microdem/microdem.htm

[18] Blender contributors (2015), blender.org - Home [Online], available at http://www.blender.org 